\title{
IDENTIFIKASI SimbOL-SIMBOL HERITAGE KERATON KASEPUHAN
}

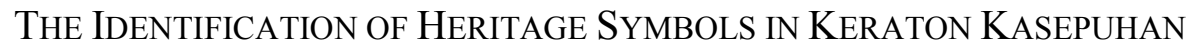

\author{
${ }^{1}$ Ina Helena Agustina, ${ }^{2}$ Hilwati Hindersah, ${ }^{3}$ Yulia Asiyawati \\ ${ }^{1,2,3}$ Program Studi Perencanaan Wilayah dan Kota, UNISBA Jl. Tamansari No 140116

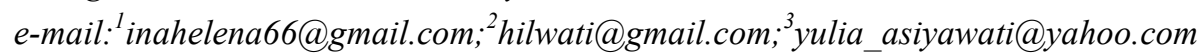

\begin{abstract}
The regulations regarding to the Indonesian government concern for the preservation of heritage space contained in Law No. 11 Year 2010 concerning the cultural heritage. Keraton Kasepuhan is a heritage room with residential space called the Magersari. But the Magersari room had the penetration change that resulting the loss of the unity space with Keraton (palace) room's "image". Thus the Magersari room doesnot attract the tourists/visitors of Keraton Kasepuhan. The purpose of this scientific writing is to identify the heritage symbols of Keraton Kasepuhan in order to present the same "image" for Magersari residential. The meaning review of Keraton Kasepuhan building phenomenon results the identification based on Husserl's phenomenology approach. Husserl's phenomenology is a method of extracting the meaning derived from the experience. The benefits of this research is to provide the policy direction for the development of Magersari residential with the Keraton Kasepuhan symbols. The results from the study indicates a typology symbol that appears in Keraton Kasepuhan such as the symbol of the flora, fauna, geometric and nature.
\end{abstract}

Keywords: Heritage, Symbol, Magersari, Keraton Kasepuhan

\begin{abstract}
Abstrak. Peraturan mengenai keperdulian Pemerintah Indonesia terhadap pelestarian ruang heritage tercantum dalam Undang-undang no 11 Tahun 2010 tentang cagar budaya. Keraton Kasepuhan merupakan ruang heritage dengan ruang permukiman yang disebut magersari. Akan tetapi ruang magersari mengalami penetrasi perubahan yang mengakibatkan hilangnya "image" kesatuan ruang dengan ruang keraton. Dengan demikian ruang magersari tidak menarik wisatawan pengunjung Keraton Kasepuhan. Tujuan penulisan karya ilmiah ini adalah mengidentifikasi simbol-simbol heritage Keraton Kasepuhan agar dapat memberikan "image" yang sama untuk permukiman magersari. Identifikasi dihasilkan dari penelaahan makna fenomena bangunan Keraton Kasepuhan melalui pendekatan fenomenologi Husserl. Fenomenologi Husserl adalah metode penggalian makna yang diperoleh dari pengalaman orang. Manfaat yang didapat dari hasil penelitian ini adalah memberikan arah kebijakan pembangunan rumahrumah magersari dengan simbol Keraton Kasepuhan. Hasil dari penelitian menunjukkan adanya tipologi simbol yang muncul di Keraton Kasepuhan yaitu simbol flora, fauna,geometris dan alam.
\end{abstract}

Kata Kunci: Heritage, Simbol, Magersari, Keraton Kasepuhan

\section{Pendahuluan}

Berdasarkan Undang-undang 11 Tahun 2010 tentang cagar budaya ditetapkan bahwa negara memiliki tanggung jawab dalam pelestarian budaya bangsa, termasuk mempertahankan keraton. Keraton Kasepuhan merupakan salah satu warisan budaya bangsa yang masih berdiri hingga saat ini. Kawasan Keraton Kasepuhan memiliki kawasan permukiman di dalam benteng keraton dengan sebutan magersari. Kawasan permukiman ini menjadi satu kesatuan dengan ruang keraton. Ruang keraton dan ruang 
permukiman magersari merupakan ruang heritage akan tetapi ruang magersari mengalami penetrasi perubahan. Salah satu wujud perubahan yang terlihat adalah berdirinya bangunan-bangunan yang mengadopsi bangunan modern. Perubahan ini tentunya mengancam eksistensi ruang keraton. Dengan demikian walaupun memiliki Undang-undang No 11 Tahun 2010 tentang cagar budaya ternyata ruang heritage membutuhkan usaha yang berkelanjutan dalam mendukung eksistensinya termasuk Keraton Kasepuhan.

Saat ini perubahan fisik rumah magersari ditunjukkan melalui bentuk rumahrumah permanen dengan gaya arsitektural bangunan modern. Bahkan terdapat beberapa bentuk bangunan bertingkat melebihi ketinggian bangunan keraton. Bangunan rumah di magersari memiliki kecenderungan padat dan kumuh. Kondisi tersebut dapat mengancam hilangnya identitas kesatuan ruang dengan ruang keraton, sehingga memiliki kesan tidak beraturan dan hilangnya citra ruang yang menyatu dengan keraton. Hilangnya kesatuan ruang akan mengurangi eksistensi ruang keraton sebagai ruang heritage yang mampu menjadi daya tarik wisatawan. Kondisi saat ini mengakibatkan magersari kurang layak menjadi bagian pendukung objek wisata Keraton Kasepuhan. Richard T, Melstrom ( 2013) mengungkapkan bahwa kealamiah budaya yang terdapat dalam ruang luar (out door) memiliki suatu nilai yang tinggi untuk daya tarik wisatawan. Cultural heritage dalam bentuk mempertahankan simbol-simbol Keraton Kasepuhan di magersari sangat penting untuk mempertahankan eksistensi Magersari sebagai ruang heritage yang menyatu dengan Keraton Kasepuhan.

Tata bangunan suatu rumah tinggal mencerminkan suatu kebudayaan tertentu. Seperti pernyataan berikut: "Houses are distinctively organised spatial networks that embody social norms and meaning of a given culture. Normally it is accepted that visually identifiable house 'types' which also closely fit the culture of a group are adopted by society" Paranagamage (2013). Pernyataan tersebut menegaskan bahwa rumah sebagai suatu bangunan memiliki suatu nilai sosial, makna dan budaya tertentu. Terutama bangunan rumah yang terdapat di magersari merupakan suatu bagian penting dalam perspektif kebudayaan. Rumah-rumah di kawasan magersari dibangun bersamaan waktunya dengan pendirian Keraton Kasepuhan. Awal pendirian bangunan rumah magersari merupakan wujud ekspresi raja dan pekerjanya. Bentuk dan ruang suatu rumah adalah hasil dari ekspresi keyakinan orang-orang yang menempatinya sesuai tatanan sosial dan waktu (Paranagamage, 2013). Tatanan sosial magersari adalah suatu tatanan sosial seorang raja dengan rakyatnya. Tatanan sosial ini berbeda dalam suatu lingkungan permukiman berlaku secara umum.

Ruang permukiman Magersari merupakan ruang yang menyatu dengan ruang Keraton Kasepuhan. Dahulu ruang magersari merupakan rumah tinggal abdi dalem ( pekerja di keraton), saat ini ruang magersari tidak lagi menjadi rumah abdi dalem. Selain perubahan kepemilikan rumah, ruang magersari mengalami pula perubahan bentuk bangunannya. Perubahan bentuk bangunan magersari mengganggu "image" magersari sebagai suatu objek wisata yang menyatu dengan keraton. Usaha untuk mengembalikan ruang magersari sebagai bagian ruang keraton membutuhkan kajian terhadap simbol heritage. Upaya ini untuk mewujudkan ruang heritage Kawasan Keraton Kasepuhan secara utuh. Rumusan masalah yang akan menjadi bahan penelitian adalah: Apa saja simbol-simbol heritage di Keraton Kasepuhan?, Apakah pesan/makna simbol heritage di Kawasan Keraton Kasepuhan? 


\section{Kajian Fenomenologis Simbol-simbol Keraton Kasepuhan}

Keraton Kasepuhan memiliki arti nama yang berasal dari Bahasa Sunda yaitu Sepuh yang berarti Tua. Keraton Kasepuhan berawal berdirinya suatu Kerajaan di Cirebon dengan nama Keraton Pakungwati, selanjutnya pada abad ke 16 dibagi menjadi 3 buah keraton yaitu Keraton Kasepuhan, Keraton Kanoman dan Keraton Kacirebonan. Dengan demikian Ketiga keraton tersebut berasal dari satu keturunan anggota walisanga yaitu Sunan Gunung Jati. Walisanga adalah kelompok wali (orang suci) yang menyebarkan Agama Islam di Pulau Jawa. Sementara dasar pembagian menjadi tiga keraton dilakukan oleh Pangeran Girilaya karena alasan untuk keadilan ketiga orang putra mahkota. Ketiga keraton tersebut hingga saat ini masih berwujud di Kota Cirebon Provinsi Jawa Barat.

Keraton Kasepuhan memiliki luas wilayah 18,5 Ha. Keraton dibatasi oleh tembok yang membentang dari Utara ke Selatan. Untuk memasuki halaman pertama terdapat jembatan Pangrawit dan pintunya hanya merupakan pemotongan tembok keliling. Sebelum memasuki halaman pertama terdapat bangunan Pancaratna di sisi barat dan Pancaniti di sisi timur jalan masuk. Pada halaman pertama di sisi timur terdapat kompleks Siti Inggil dan bangunan Pengada. Untuk memasuki halaman ke dua terdapat Langgar Dalem di sisi barat, melalui dua gapura paduraksa. Demikian juga pada tembok pembatas antara halaman ke dua dan halaman ke tiga terdapat gapura paduraksa.Pada halaman ke tiga terdapat bangunan lunjuk, Srimanganti, Gedung Kereta, Museum dan bangunan inti.

Sistem ruang Keraton Kasepuhan mengadopsi seni bangunan yang berkembang pada masa Majapahit. Selain itu masih adanya kepercayaan alam pikiran pada masa pra-Islam yaitu tentang Kesejajaran antara alam semesta dan alam manusia. Kosmo magis yang bersumber pada ajaran kosmologis Hindu dan Budha. Sebagai gambaran atau cerminan alam semesta menurut kepercayaan itu, bahwa Keraton beserta seluruh isinya dianggap sebagai replika atau tiruan alam semesta, contohnya raja yang bersemayam di istana disamakan dengan dewa yang bersemayam di puncak Mahameru. Salah satu pengejawantahan kepercayaan peniruan kosmos mahameru melalui seni bangunan yang paling menonjol adalah bangunan candi, dengan demikian pengambaran gunung merupakan suatu motif yang mewisesa dalam seni bangunan Jawa Hindu.

Satu ciri penting lainnya yang juga dianggap sebagai kesinambungan alam pikiran Jawa Hindu yang berpengaruh atau mengilhami perkembangan seni bangunan Kraton Kasepuhanadalah pembuatan bukit dan kolam buatan dengan suatu gugusan bangunan yang terletak di tangannya. Di Keraton Kasepuhan terdapat dua buah bukit buatan yang disebut gunung yaitu Gunung Indrakila dan Gunung Semar. Sedangkan dalam bentuk bangunan kolam buatan dengan gugusan bangunan ditengahnya disebut Balong Klangenan. sedangkan bangunan kayu di tengahnya dinamakan Bale Kembang ( Agustina, 2013;2014). Aspek lainnya adalah tata letak bangunan Kompleks Keraton ke dalam tiga bagian. Kontur permukaan dan pelataran Kompleks dibuat semakin meninggi ke belakang, yang menunjukan derajat kesucian dan merupakan bagian paling suci, karena bagian ini merupakan tempat bersemayam raja beserta seluruh keluarganya. (lihat gambar 1 berikut yang menjelaskan struktur kosmologi keraton kasepuhan). 


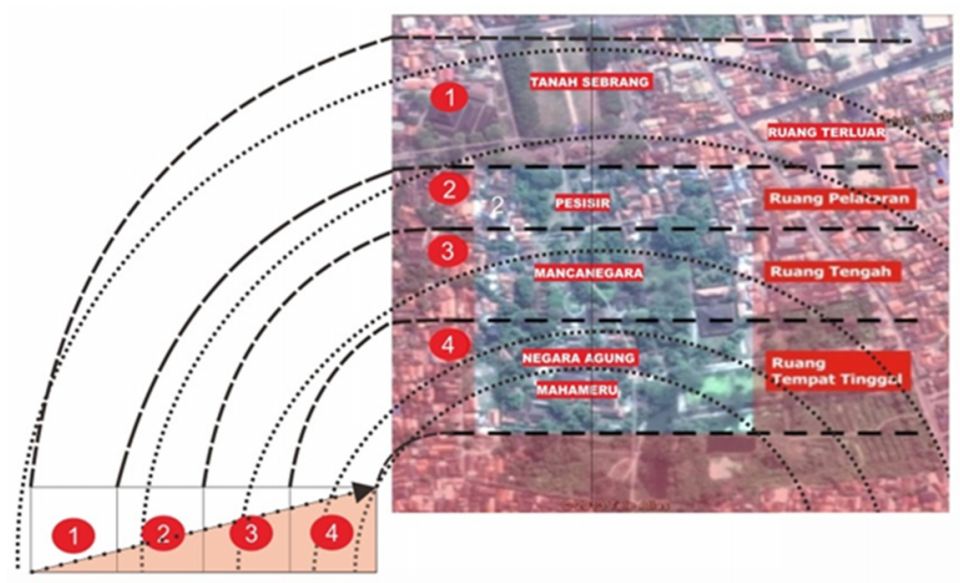

SEMAKIN MENINGGI (MENUNJUKAN DERAJAT KESUCIAN DAN KEAGUNGAN

\section{Gambar 1. Struktur Keraton Kasepuhan}

(Sumber: Agustina, 2013)

Penelitian ini merupakan lanjutan dari penelitian disertasi. Peelitian Disertasi menggunakan penelitian fenomenologi Husserl. Dengan demikian penelitian ini menjadi semakin mendalam melihat fenomena keruangan Kawasan Keraton Kasepuhan. Awal penelitian disertasi dilakukan pada tahun 2010 secara terus menerus hingga berlanjut pada kegiatan penelitian ini (tahun 2016). Proses fenomenologi telah terinternalisasi dalam proses waktu oleh peneliti. Informasi yang diperoleh sebelumnya menjadi bagian penting dalam pemahaman peneliti untuk menjadi Grand Tour pada penelitian yang baru. Informasi-informasi baru dikumpulkan satu demi satu sesuai dengan pengelompokkan hasil observasi baik wawancara maupun visual. Selanjutnya informasi lama maupun baru dipelajari kembali dan dipahami kembali untuk dikelompokkan menjadi unit-unit informasi. Dari unit informasi yang sama dikelompokkan menjadi kelompok-kelompok tema simbol. Unit informasi dikelompokkan berdasarkan lokasi keruangan Keraton Kasepuhan. Temuan studi menghasilkan tema-tema berdasarkan kelompok simbol tersebut kemudian diintepretasi maknanya.

\section{Kategorisasi Simbol-simbol dan Intepretasi Makna}

Magersari merupakan suatu ruang yang memiliki pemahaman terhadap pola memagari atau membentengi atau menjaga keraton. Dengan demikian maka magersari merupakan permukiman yang sekelilingnya di bentengi oleh benteng-benteng keraton. Magersari merupakan ruang yang diperuntukkan raja kepada abdi dalem keraton. Abdi dalem adalah mereka yang bekerja di keraton. Dengan demikian maka fungsi utama ruang magersari adalah sebagai permukiman abdi dalem keraton. Berikut ini dapat dilihat posisi magersari pada Kawasan Keraton Kasepuhan ( lihat gambar 1). 


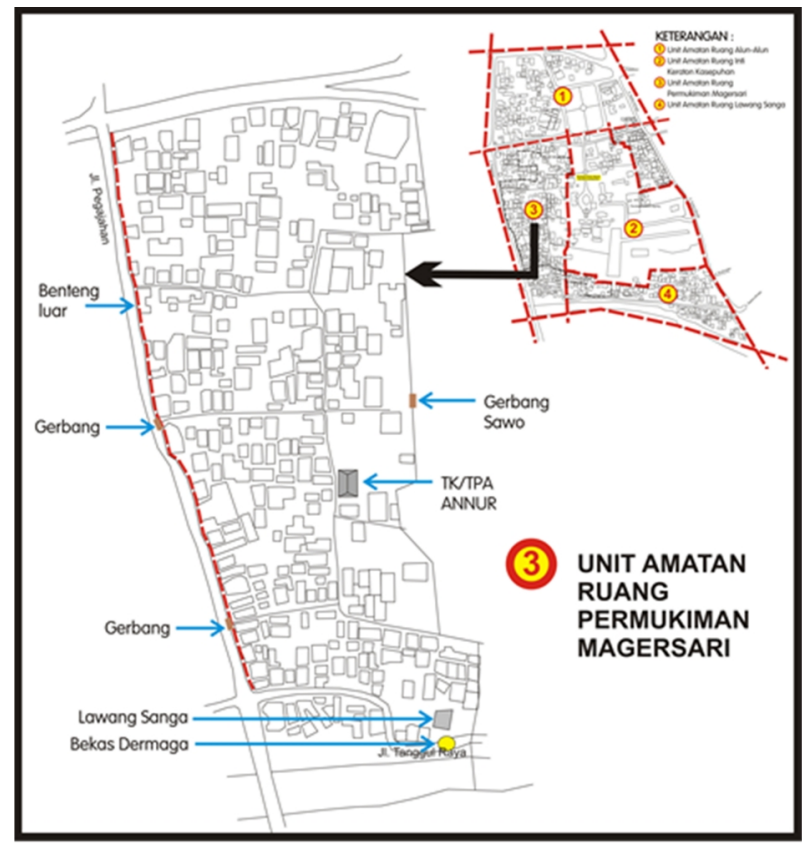

\section{Gambar 1 Posisi Magersari di Keraton Kasepuhan}

(Sumber ;Agustina, 2013)

Secara garis besar permukiman Magersari adalah suatu kawasan yang berada di sekitar Keraton Kasepuhan. Komplek permukiman ini dibangun bersamaan dengan berdirinya Padepokan Pakungwati pada abad ke 14 M. Pendirinya adalah Pangeran Cakrabuana. Inilah yang menjadi asal usul sejarah berdirinya Kota Cirebon dan Keraton Kasepuhan. Kawasan permukiman Magersari, memiliki batas wilayah sebagai berikut : Sebelah utara : parit/ kali, jalan utama, Masjid Agung Sang Cipta Rasa, Sebelah Selatan : Kali Kriyan ,Sebelah Barat : Jalan utama, permukiman penduduk, Sebelah Timur : Keraton Kasepuhan. Tembok pembatas/benteng memiliki tinggi sekitar 2 meter. Tembok tersebut dibangun untuk membatasi ruang kawasan dengan permukiman di luarnya. Berdasarkan pengamatan yang terus menerus dari tahun 2010-2016 dengan pendekatan fenomenologi terhadap fenomena Kawasan Keraton Kasepuhan maka dapat dikelompokkan fenomena simbol seperti yang terlihat pada tabel berikut.

Tabel 1. Kategorisasi Simbol-simbol

\begin{tabular}{|c|c|c|c|}
\hline No & Unit Informasi & Intepretasi dari Unit Informasi & Kategorisasi Simbol \\
\hline 1 & $\begin{array}{l}\text { Simbol di Ruang Tanah } \\
\text { Sebrang }\end{array}$ & $\begin{array}{l}\text { Bangunan Masjid Ciptarasa dan Alun- } \\
\text { alun merupakan bangunan yang } \\
\text { masuk dalam unit ruang Tanah } \\
\text { Sebrang. Alun-alun terdiri dari } 4 \text { buah } \\
\text { gapura yang menyerupai gapura } \\
\text { bentar. Di Ruang Masjid Agung Cipta } \\
\text { Rasa penuh dengan simbol geometris } \\
\text { dan simbol flora berbentuk Bunga } \\
\text { Teratai. Simbol bunga teratai terlihat } \\
\text { di bagian dinding Mihrab dan dibagian } \\
\text { ruang Mihrab bagiaan atas kepala. } \\
\text { Sedangkan bentuk geometris } \\
\text { menyerupai bunga terdapat di pintu } \\
\text { masjid dan Benteng Masjid. }\end{array}$ & $\begin{array}{l}\text { - Simbol Flora } \\
\text { - Simbol Alam } \\
\text { - Simbol Geometris }\end{array}$ \\
\hline
\end{tabular}




\begin{tabular}{|c|c|c|c|}
\hline No & Unit Informasi & Intepretasi dari Unit Informasi & Kategorisasi Simbol \\
\hline & & $\begin{array}{l}\text { Bangunan Masjid ditopang oleh Soko } \\
\text { Guru ( Tiang besar berdiamer } 30-40 \\
\mathrm{~cm} \text { ) terbuat dari kayu. Pintu masuk ke } \\
\text { dalam Masjid harus membungkuk } \\
\text { karena ukuran pintu yang rendah di } \\
\text { bagian kepala. }\end{array}$ & \\
\hline 2 & Simbol Di Ruang Pesisir & $\begin{array}{l}\text { Bangunan Yang ada di ruang pesisir } \\
\text { adalah Pancaratna dan Pancaniti serta } \\
\text { Siti Inggil. Bangunan Pancaratna dan } \\
\text { Pancaniti berada di bagian depan } \\
\text { sebelum masuk ke halaman pertama } \\
\text { keraton. Bangunan Pancaratna dan } \\
\text { Pancaniti memberikan simbol-simbol } \\
\text { yang terdapat pada tiang-tiangnya. } \\
\text { Bangunan Siti Inggil adalah bangunan } \\
\text { yang menjadi sarana "show room" } \\
\text { keraton. Terdapat bangunan Semar } \\
\text { Tinandu yaitu bangunan dengan dua } \\
\text { buah tiang berbentuk Demak } \\
\text { Kaliangan berkaki tiga. Dua tiang } \\
\text { merupakan simbol dua kalimat } \\
\text { Syahadat. Bangunan lainnya adalag } \\
\text { Mande Karesmen, Mande Pengiring, } \\
\text { Malang Semirang dan Pandawa lima. } \\
\text { Dinding di Siti Inggil terdapat keramik } \\
\text { terbuat dari Eropa dengan gambar- } \\
\text { gambar manusia maupun bunga. } \\
\text { Sedangkan di bagian tangga terdapat } \\
\text { sengkalan memet berbentuk banteng. }\end{array}$ & $\begin{array}{l}\text { - Simbol Flora } \\
\text { - Simol Fauna } \\
\text { - Simbol Geometris } \\
\text { - Simbol Alam Semesta }\end{array}$ \\
\hline 3 & $\begin{array}{l}\text { Simbol Di } \quad \text { Ruang } \\
\text { Mancanegara }\end{array}$ & $\begin{array}{l}\text { Di Ruang Manca negara terdapat } \\
\text { ruang museum Singa barong dan } \\
\text { Museum Benda kuno serta Masjid } \\
\text { Dalem Ageung.Pada bangunan ini } \\
\text { terdapat simbol-simbol flora, Fauna } \\
\text { dan alam semesta. Terutama di } \\
\text { Bunderan Dewandaru terdapat patung } \\
\text { nandi dan macan. }\end{array}$ & $\begin{array}{l}\text { - Simbol Flora } \\
\text { - Simbol Fauna } \\
\text { - Simbol Alam Semesta } \\
\text { - Simbol Geometris }\end{array}$ \\
\hline
\end{tabular}




\begin{tabular}{|c|c|c|c|}
\hline No & Unit Informasi & Intepretasi dari Unit Informasi & Kategorisasi Simbol \\
\hline 4 & $\begin{array}{l}\text { Simbol di Ruang Inti } \\
\text { Keraton } \\
\text { Puncak Mahameru) }\end{array}$ & $\begin{array}{l}\text { Ruang yang terdapat di Keraton dan } \\
\text { Bangunan Inti Keraton. Bangunan Inti } \\
\text { merupakan bagian dari Tempat tinggal } \\
\text { Raja dan aktivitas Raja sebagai simbol } \\
\text { kekuasaan. Ruang-ruang dibangun } \\
\text { dengan sistem keruangan yang } \\
\text { membentuk keterpaduaan antara } \\
\text { makrokosmos (jagat raya dan } \\
\text { mikrokosmos ). Terjadi perubahan } \\
\text { fungsi ruang dan ruang-ruang ini } \\
\text { masih digunakan sebagai pelaksanaan } \\
\text { tradisi esoterik termasuk tradisi } \\
\text { tawasulan. }\end{array}$ & $\begin{array}{l}\text { - Simbol Flora } \\
\text { - Simbol Fauna } \\
\text { - Simbol Alam Semesta } \\
\text { - Simbol-simbol } \\
\text { Geometris }\end{array}$ \\
\hline
\end{tabular}

Sumber : Tim, 2016

Berdasarkan penjelasan di atas maka simbol-simbol dapat dikategorisasikan sebagai bentuk flora ,fauna, geometris dan alam. Selain simbol tersebut Keraton Kasepuhan penuh dihiasi oleh bentuk keramik-keramik yang berasal dari Eropa maupun Cina. Fenomena ini menunjukkan bahwa terjadi hubungan antara keraton dengan negara asing seperti Eropa dan Cina. Hubungan ini tentunya didukung oleh letak keraton yang berada dekat dengan perairan laut Jawa. Simbol relasi ke wilayah tersebut masih dapat terlihat hingga saat ini. Motif simbol yang banyak berulang adalah bunga teratai. Setiap bagian sudut keraton dihiasi oleh bunga teratai. Bunga teratai juga terdapat di bagian luar bangunan gedung keraton inti maupun di tangga menuju ruang panembahan, terdapat pula di bangunan museum sigabarong dan museum di sayap kiri keraton. Bagian mihrab tempat berdirinya Imam Masjid Sang Cipta Rasa terdapat bunga teratai bahkan di Langgar Pangrawit terdapat pula motif teratai. Motif daun teratai terdapat pula di Malang Semirang, Mande Karesmen dan Mande Pengiring. Simbol bunga teratai memberikan suatu replika kehidupan bunga teratai yang dapat berbunga indah sekalipun berada di air yang kotor. Ini mereplika petatah-petitih dari Sunan Gunung Jati yaitu Ingsun Titipna Tajug dan Fakir Miskin yaitu titip tempat ibadah dah kaum miskin.

\section{Kesimpulan dan Saran}

Berdasarkan rumusan masalah, hasil penelitian dan pembahasan yang disajikan sebelumnya maka dapat ditarik kesimpulan sebagai berikut : (1) Simbol-simbol heritage di Keraton Kasepuhan. Adalah simbol flora, fauna, geometris dan alam semesta, (2) Pesan/makna simbol heritage di Kawasan Keraton Kasepuhan adalah makna yang berhubungan dengan kehidupan manusia untuk menampilkan segala kebaikan-kebaikan pada ummat terutama kaum marginal.

Berdasarkan kesimpulan di atas, peneliti mengusulkan beberapa rekomendasi untuk tata bangunan rumah di Magersari agar memunculkan simbol bunga teratai sebagai bagian bangunannya. Simbol bangunan dapat diletakkan pada bagian pagar maupun bagian genting. Dengan demikian "image" Keraton Kasepuhan akan menyatu dengan Magersari. Untuk mewujudkan ini maka pihak Keraton dapat membuat suatu ketentuan atau aturan tata bangunan di Kawasan Magersari. 


\section{Daftar pustaka}

Agustina, Ina Helena, (2015), Pergeseran Makna Ruang Simbolik Ke Ruang Pragmatis Kawasan Keraton Kasepuhan Cirebon, Disertasi Tidak Dipublikasikan, Fakultas Teknik Universitas Gadjah Mada.

Agustina, Ina Helena, Hilwati Hindersah, Yulia Asyawati. (2016), Kajian Cultural Heritage Kawasan Permukiman Magersari Keraton Kasepuhan, Laporan Penelitian dan Pengabdian Masyarakat, Universitas Islam Bandung.

Agustina, Ina Helena, Achmad Djunaedi, Sudaryono, Djoko Suryo. (2012). Fenomena Ruang - Ruang di Kawasan Keraton Kasepuhan Cirebon, Jurnal Perencanaan Wilayah dan Kota,Unisba Vol 12/ No 2 . Hal 5-11.

Agustina, Ina Helena, Achmad Djunaedi, Sudaryono, Djoko Suryo. (2013). Perempuan Dan Ruang Kawasan Keraton Kasepuhan, Jurnal Perencanaan Wilayah dan Kota,Unisba Vol 13 /No.1. Hal 6-12.

Agustina, Ina Helena, Achmad Djunaedi, Sudaryono, Djoko Suryo. (2013). Gerak Ruang Kawasan Keraton Kasepuhan, Jurnal Perencanaan Wilayah dan Kota,Unisba Vol 13 /No.2 Hal 8-13.

Agustina, Ina Helena, Achmad Djunaedi, Sudaryono, Djoko Suryo. (2013). The Perspective Of Sustainable in Relation Space at Region Of Kasultanan Kasepuhan Cirebon, Makalah dipresentasikan dalam konferensi Internasional ICABE di IIUM, Kulalumpur, $7^{\text {th }}-8^{\text {th }}$ November.

Agustina, Ina Helena, Achmad Djunaedi, Sudaryono, Djoko Suryo. (2013). Transformation Meaning Of Space in Keraton Kasepuhan, Makalah dipresentasikan dalam konferensi Internasional ICABE di IIUM, Kulalumpur, $7^{\text {th }}-$ $8^{\text {th }}$ November.

Agustina, Ina Helena, Achmad Djunaedi, Sudaryono, Djoko Suryo. (2014). Kajian Fenomena lokal : Model Siklus Perubahan Ruang Tradisi Panjang Jimat Kawasan Keraton Kasepuhan, Bandung, Makalah ini dipresentasikan pada Seminar Nasional Fakultas Teknik Unisba, Bandung 22 Mei.

Agustina, Ina Helena, Hilwati Hindersah, Imam Indratno. (2014). Kajian Makna Ruang Tradisi Esoterik Kawasan Keraton Kasepuhan, Makalah ini dipresentasikan pada seminar nasional - Snapp, Unisba, Bandung 29 Oktober.

Agustina, Ina Helena. (2015). Kajian Nilai Ruang Permukiman Magersari Kawasan keraton Kasepuhan Cirebon,Laporan Penelitian. Bandung: Lembaga Penelitian dan Pengabdian Kepada Masyarakat, Universitas Islam Bandung.

Melstrom, Richard . (2015). Valuing a historic site with multiple visitor types and missing survey data, (on line) www.elsevier.com/journals/ diakses 20 Desember 2015).

Paranagamage, Primali . (2013). Changing Boundaries and Meaning Of Middle Class Houses in Sri lanka, (online), (www.isvs.com/journal.aspx diakses 20 Desember 2015) .

UNDANG-UNDANG REPUBLIK INDONESIA NOMOR 11 TAHUN 2010

TENTANG CAGAR BUDAYA 